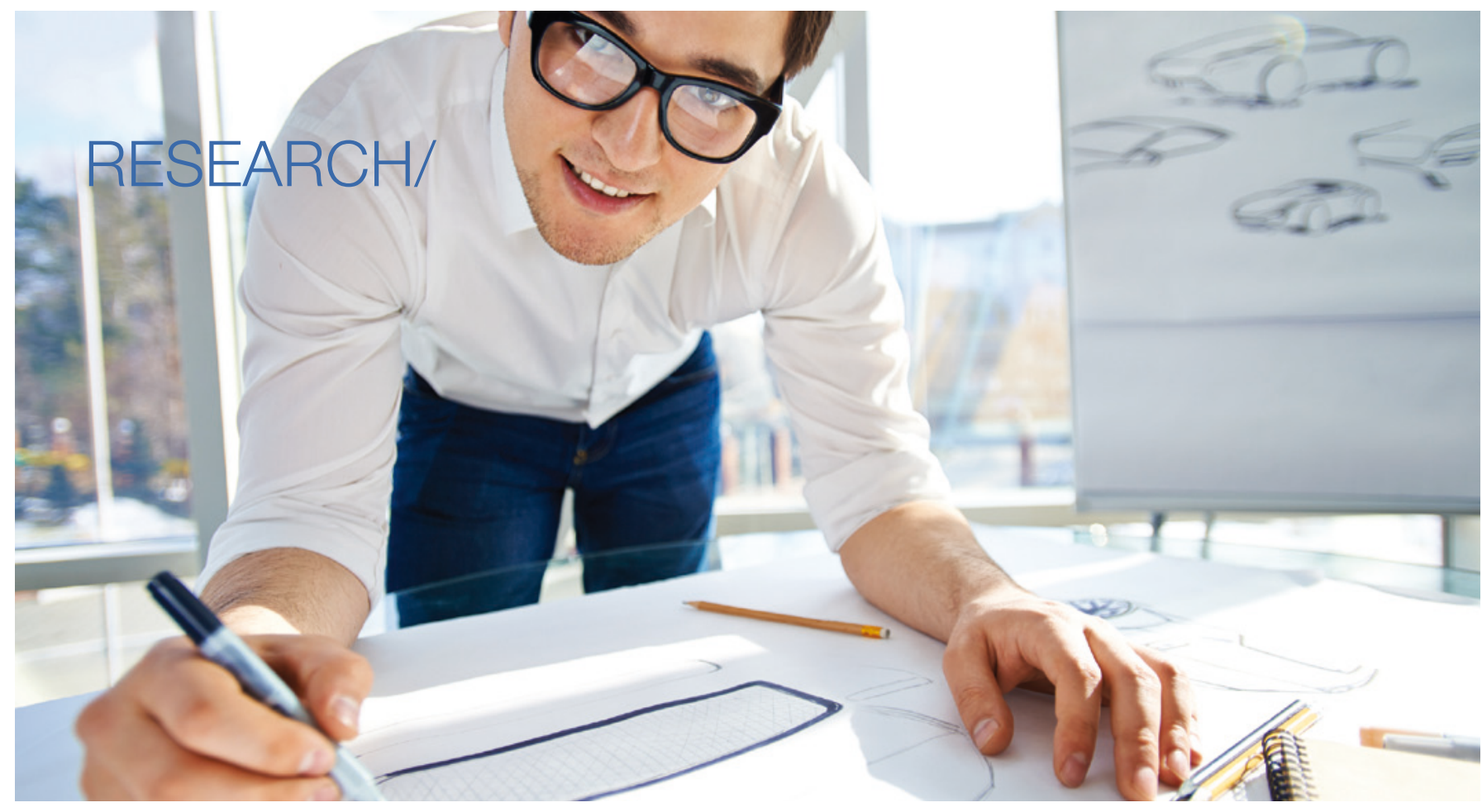

\title{
Beyond ICT: How industrial design could contribute to $\mathrm{HCl}$ research
}

\section{What happens to knowledge related to design activities and skills, when these are primarily understood in the light of Information and Communication Technology (ICT)?}

THIS PAPER TAKES AN industrial design practitioner perspective to reflect on the articulation of 'design' in Human Computer Interaction (HCI) research - one of several research fields, articulating and contributing to design knowledge. The paper critically reflects on the importance of more holistic perspectives for design activities, and the articulation of design in HCI research. We argue that industrial design practitioners can contribute to $\mathrm{HCI}$ research by broadening the design knowledge and the practice within the field not to view ICT as a self-evident part of either a solution or as a tool in the process of specifying the problem or finding a solution. This may not only improve the articulation of design and design activities, but more importantly point towards an opportunity to support more socially and environmentally sustainable solutions in society.

\section{Introduction}

Typically, research discussing concerns of design practice and approaches is not conducted by design practitioners (Forlizzi, Zimmerman, \& Stolterman,
2009; Johansson-Sköldberg, Woodilla, \& Çetinkaya, 2013). This becomes problematic when the research contributes to the articulation of design knowledge, but does not match with practitioners' perspectives of design activities and design skills. In HCI research, several researchers have problematized the difference of design practice conducted among interaction design professionals and how it is articulated in research (Frankel Q Racine, 2010; Goodman, Stolterman, Q Wakkary, 2011; Mullaney QX Stolterman, 2014; Roedl Q Stolterman, 2013; Stolterman, 2008). 
In this paper, we take a professional industrial design perspective to reflect on HCI research and some of its related design activities, to clarify core differences between this and the industrial design practice. Thus, in this paper industrial designers are articulating research on design in HCI research - rather than the opposite.

Industrial design is practiced in a variety of domains in society today, such as service design, user experience design, product design or strategic design. It is increasingly becoming acknowledged as a more general process and methodology that can contribute at different levels of more or less "wicked problems" (Buchanan, 1992; Valtonen, 2007) and in innovation work (Freire \& Sangiorgi, 2010; Jahnke, 2013; Wrigley \& Bucolo, 2011). Industrial design knowledge has been described from many perspectives. Our perspective is related to design as meaning-making, where the process and the results may be interpreted as meaning creation (Johansson-Sköldberg et al., 2013; Krippendorff, 2006; Verganti, 2009). It is also related to essentially concern understanding and addressing the meanings and needs that people have (Krippendorff, 2006; Verganti, 2009). We agree that ability to "change meaning" is related to the ability of re-framing design challenges (Dorst, 2011), requiring divergent thinking (Rhea, 2003). We also consider design skills to be related to abduction, where several aspects of a design challenge involve uncertainty and are given a new frame or value during the process (Dorst, 20IO). However, we do not agree with a view upon industrial design as a field of competence being product-oriented and three-dimensional, as described in Koskinen et al. (Koskinen, Zimmerman, Binder, Redstrom, Q $Q$ Wensveen, 2011). Based on our experiences as practitioners, we instead agree with Valtonen (2005) taking the perspective that the competence of the industrial designer can be understood in a broader sense; to contribute with a holistic perspective aiming at sustainable and innovative solutions.

\section{Our perspective is related to design as meaning-making, where the process and the results may be interpreted as meaning creation"}

\section{Author perspectives}

This paper will reflect upon differences in specific design activities and methods as they are articulated in HCI research, from an industrial design perspective. The background is that the authors for several years have witnessed contradictions arising from comparing design activities as they are viewed upon in industrial design practice and in $\mathrm{HCI}$ research, respectively.

Anna Thies has her educational base in a Master of Fine Arts (MFA) degree in industrial design. She has io years' experience of teaching industrial design students and has broadened her qualifications towards interaction design. She is currently conducting PhD studies within the context of HCI and has conducted several service-design-based projects within innovation and development in healthcare. Coming from an art-based design education, conducting her $\mathrm{PhD}$ within an academic context of HCI gave her an eye-opening insight into the gap between two different views upon design.

Sara Ljungblad has an inverse background from Thies, coming from conducting her PhD within $\mathrm{HCI}$, to conducting a three-year post-doc at an industrial-design-based design and innovation agency. Within the process of her post-doc she has held several interviews and extensive discussions with industrial design practitioners. She is currently employed as a researcher and assistant professor at a department for Applied IT at a Swedish university.

Iréne Stewart Claesson has her background in industrial design with over 25 years of experience. She is a well-established design consultant with her own design and innovation agency where Ljungblad conducted her postdoc. The agency has a focus on using design methods to develop sustainable, norm-critical design and social innovations. She has launched cross-sectorial initiatives to develop the field of design and has initiated and developed a master education in Business \& Design.

Based on this background we wish to expand and share our reflections and professional experiences in this paper. We will first introduce readers to the field of $\mathrm{HCI}$ research and interaction design. We then discuss the problem of design fixation, which we argue that ICT constitutes in design research within HCI. We then describe and illustrate how skilled industrial design practitioners strive for keeping an open mindset - based on the needs of the stakeholders to avoid design fixations. Finally, we discuss the potential value and risks of such an approach for HCI research.

\section{Human Computer Interaction (HCl) research}

Today, many techniques and approaches within design related research in HCI are described as research through design, and are understood and articulated as design methods and design approaches (e.g. Buchenau \& Suri, 2000; Hutchinson et al., 2003; Iacucci, Kuutti, \& Ranta, 2000). Research in HCI brings a specific perspective of design activities and design as knowledge by primarily seeking out to explore and understand design in relation to use of computer technology; predominantly concerning change and implications for design of novel computing technologies (Bardzell, Bardzell, DiSalvo, Gaver, \&2 Sengers, 2012). Several sciences and practices, such as social science, computer science, cognitive science, psychology as well as design 
contribute to $\mathrm{HCI}$, and thus also to the articulation of design.

Researchers in HCI articulate metaperspectives on design knowledge, such as proposing design methodology and clarifying the role of design in research (e.g. Fallman, 2003; Sengers \& Gaver, 2006; Zimmerman, Forlizzi, \& Evenson, 2007). Even if HCI research may explore humanistic aspects such as empathy, users and needs, the research is essentially oriented on how human computer interaction design may contribute to our lives and society (Fallman, 2003). This brings specific socio, cultural and environmental consequences to our society (Bardzell et al., 2012) and also challenges the notion of design when research on ICT-supported solutions represent a multitude of design-research.

HCI research has been criticized to encourage an understanding of needs as implications for design (Dourish, 2006). When understanding needs in a demarcated realm as for example in relation to a technology, this may limit the possibility to understand needs beyond the ones that in some way relate to the technology. For example, design approaches in HCI research can involve understanding experiences and needs by matching specific technology properties with a specific practice or needs - to give rise to new ideas of technology applications (e.g. Ljungblad Q Holmquist, 2007). Even if such an approach successfully may explore technological properties and related experiences, it fixates the process on exploring a specific technology when used early in the process.

This design orientation with its strong connection to ICT has been problematized by for example by Baumer and Silberman. They question the design approach in HCI research by proposing what they call "technology extraventions" to describe cases when ICT should acti-

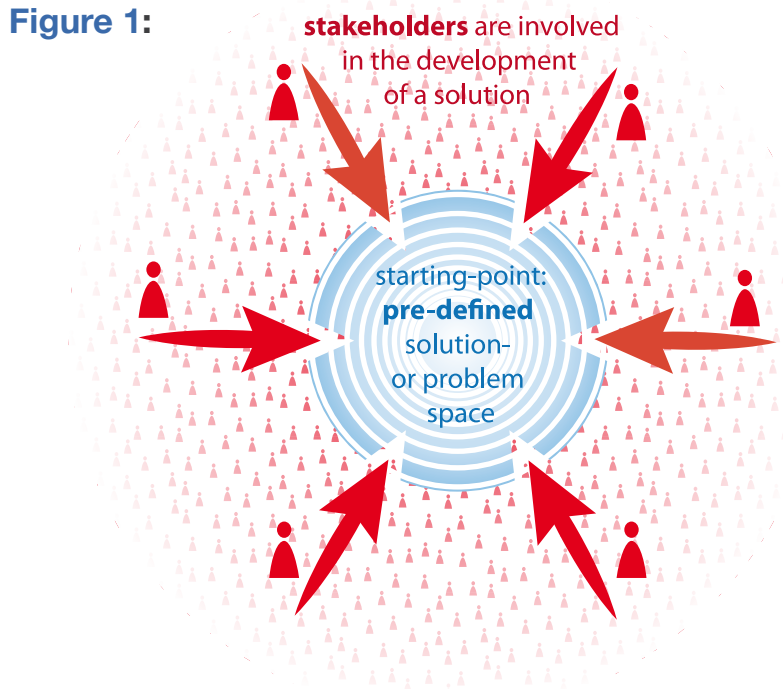

Figure 1: The stakeholder involvement process with a pre-defined problem- or solution space as central onset.

vely be removed or considered not to be part of a solution (Baumer \& Silberman, 2011). They discuss how an increased focus on the problem space is needed, but they do not discuss how an industrial design perspective could contribute to alternative perspectives. Typically, not to use ICT as a tool or a solution is rarely discussed in HCI (Pierce, 2012), with some exceptions (e.g. Baumer, Burrell, Ames, Brubaker, Q D Dourish, 2015; Baumer Q Silberman, 2011; Pierce, 2012; Satchell Q Dourish, 2009). Possibly due to the term - Human Computer Interaction - itself, intrinsically implying the involvement of ICT. Nevertheless we argue that HCI research could benefit from a more holistic perspective on design related activities, requiring stepping back from a fixation on technology.

A related challenge is that some researchers argue that everyone is a designer (e.g. Norman, 2004). This is problematic as it reduces the understanding of design as a competence involving specific skills, and how those are reflected in practice
(Buxton, 2007). We believe that the understanding that anyone is a designer may be one of the reasons for why HCI research is not producing suitable tools for professional interaction designers, and that there is a lack of knowledge transfer and a gap between how theory is conceptualized in relation to the demands of doing design (e.g. Goodman, Stolterman, QT Wakkary, 2011; Rogers, 2004; Stolterman \& Pierce, 2012). This creates undesirable effects on the articulation of design, and its applicability for professional practitioners. Moreover, when researchers are conducting and articulating design, without being educated in design or lacking an overall understanding of design methodology this has an effect on the research. One example of this is the design approach, called "cultural probes" that has been heavily misunderstood as a scientific research method, when used by HCI researchers without a design background (Boehner, Vertesi, Sengers, \& Dourish, 2007; Vetting Wolf, Rode, Sussman, \& Kellogg, 2006). Thus, from an industrial design perspective,

\footnotetext{
1 In this paper we will consciously avoid the term 'user' which is commonly used in design literature, in favour of the broader notion of 'stakeholder'. A stakeholder, as we use the term, includes the user as well as other people who have legitimate interest in, or are affected by a project or entity (Smith \& Fischbacher, 2000).
} 
skilled designers have a specific competence built on experience and skills that is far beyond copying and pasting others' design approaches into new projects.

\section{Avoiding design fixation}

Skilled industrial designers actively work on keeping a holistic perspective early in the process, and to avoid fixating on solutions or perspectives early in the process. Terminologies used in academia and in engineering to describe this fixation are design fixation and functional fixedness, which are considered a cognitive bias (Jansson \& Smith, 1991; Purcell \& Gero, 1996). Without experience and design skills, the fixation may easier occur and lead to favouring one or several solutions, reducing the ability to stay open to understand alternative and holistic perspectives. This reduces the potential outcome. Design fixation or functional fixedness is often referred to by industrial design consultants when being involved in a project too late. This drastically reduces the power of design, leaving the designer with little or no space for radical changes and perspectives raised from users' needs; there is simply no room to change meaning, and the potential openings for more relevant solutions are closed.

In HCI research, technology can be developed and used in very early phases in projects, to stimulate ideas and get feedback from users. We believe that this may have its roots in software development, viewing design and the build phase as synonymous (Buxton, 2007). "Technology probes", for example, are described as a design method that is used in early phases to trigger ideas for applications. Technology probes are simple, flexible and adaptable technologies that are field-tested by users, and understood as an approach to create new technologies and to co-design with users (Hutchinson et al., 2003). Typically, a technology probe is used to collect data and/or as an early prototype of an idea. Potentially, technology probes can be used in different ways. For example, a technology probe can be used to document and understand users' routines etc. without being understood as early prototypes of a solution (Boehner et al., 2007). Thus, this is very different from a design process with more distinct phases separating research, design and construction, where the research concerns to critically investigate and reflect on needs, and what the question is really about, before suggesting design opportunities. When designing becomes synonymous with building something, there is a phase missing - the phase to define what is to be designed.

In industrial design it is common to question the very starting-point or design brief of a project in order to orient the design activity towards the right need. From an industrial design perspective, this questioning should precede the design process, as it is commonly described in HCI. Löwgren and Stolterman mention that the design process starts by designing the design process (Löwgren Q Stolterman, 2004) in order to elaborate what is to be designed. The research phase thus concerns to grasp and collect wide variety of aspects and perspectives, in order to be able to re-frame ones understanding of a situation. In the coming sections, we will explore this perspective further.

\section{Stakeholder involvement vs. stakeholder-based onsets}

From the perspective of a trained industrial designer, much HCI research has a kind of fixation on only creating a specific type of solutions or using specific types of ICT-related tools in the process. This brings specific socio, cultural and environmental consequences to our society - and to how design is understood. Design projects, whether conducted in $\mathrm{HCI}$ research or in interaction design

\section{Figure 2:}

Figure 2: Stakeholder-based development without pre-defined solution- or problem space. Instead the solution-space encompasses the central onset or starting-point: the stakeholders' needs, wishes and limitations.

2 A 'design brief' is by industrial designers commonly referred to as the initial description of a design assignment formulated by the customer. 
practice, tend to have a more or less defined starting-point. This might involve a potential type of solution, or a defined problem space i.e. a problem space that to some extent may be addressed by using ICT.

In processes commonly referred to as user involvement the user (or stakeholder) is involved in the development of a solution, thus adapting the solution to the user (see figure 1). This process is often referred to as user-centred. We question this.

Our critique does not concern user-involvement, which we agree is a valuable asset in design. Our concern is the starting-point: As long as the mindset is set on a limited problem- or solution space, such as a fixation to use ICT as a tool or part of a solution, it cannot be fully user- or stakeholder-centred.

We argue that HCI through its strong connection to ICT limits its potential solutions early on in the design process by commonly having ICT as a part of the design process or the solution. This leads to a limited solution space and to what we argue is a form of design fixation.

\section{Avoiding design fixation by star- ting through stakeholders' needs} We wish to shed light on the importance of actively avoiding design fixation. Instead we want to highlight the value of stepping back and investigating the stakeholders' needs, wishes and limitations prior to defining a possible solution space or delimitating how to attain a possible solution. This opens up for more, potentially relevant solutions or tools to use in order to develop solutions for, and with, stakeholders. (See figure 2)

This supports more humanistic, socio-focused solutions as well as more accurate problem formulations since the stakeholder is part of the process to define a possible direction of the design process, potentially not involving ICT.
This can be interpreted as a pre-process and concerns deciding what type of solution or problem exploration best might fit the stakeholders. We argue that a proper user-centred onset only can be claimed if preceded by this pre-process.

This openness to what to design, or to e.g. design an "extravention" as described by Baumer and Silberman (2011), is what we argue as the core in a pre-process that industrial designers consider self-evident.

We will illustrate this through the case of an industrial design consultancy work. Though this case does not include ICT, it illustrates what we argue as being a central aspect in industrial design practice: Questioning the initial idea of what problem to address, tool to use or solution to develop while having an open onset to what and how things might be designed.

\section{Industrial design case example}

The example below is based one of the author's practitioner experience of working as a designer with a municipality. The project took place at a Swedish design and innovation consultancy, working primarily with business-to-business clients. The case is chosen to illuminate how a proposed design-brief or startingpoint in a project can be questioned during the process, and how designers actively may work on questioning what and how to design in order to meet more relevant needs than initially aimed at. In a government funded $R \& D$ program, the city council of a middle-sized industrial town, Olofström, wanted industrial designers to design a souvenir based on spill material from a local industry. This was the starting-point.

Instead of focusing the design process on spill material opportunities, the designers started to investigate the underlying motivations and needs from different stakeholders perspectives and inhabitants, such as the municipality, a tourist centre, visitors and locals and engaged local organizations and associations.
This process led them to question the need and desire for a traditional souvenir, since the visitors were not primarily tourists.

The study showed that the small industrial town had several qualities that could be taken in consideration. It had a rich multi-cultural population living in peacefully with each other, with almost no unemployment and no apparent tensions between groups. However, a challenge was that the people were moving away because the town was seen as merely a work place, without any attractions for women, youngsters and family needs. Visitors were mainly family members from another country, or people that visited due to business.

The designers found that the municipality rather needed solutions that could strengthen the inhabitants' pride of the city and the visitors' experience of the town. In fact, local organizations could strengthen their own and the city identity.

In the end, the suggested solutions included development of a symbolic pastry from a bakery, a cookbook with dishes from the different cultural groups represented in town to manifest the uniqueness of the society. Moreover, a piece of jewellery from the local goldsmith (with the same local symbol as the pastry), and proposals for how to support visitors to explore fishing and nature areas were suggested. Overall, the designers' suggestions supported the municipality to understand how to strengthen the experience of the town, instead of simply creating a souvenir. Thus, part of the process, was also to engage the municipality in changing their perspective of what the design process should end up in, and why.

This case illustrates how the industrial designer's approach to design commonly involves to study and to question the initial assignment, before commencing the design process or creating any solu- 
Figure 3:

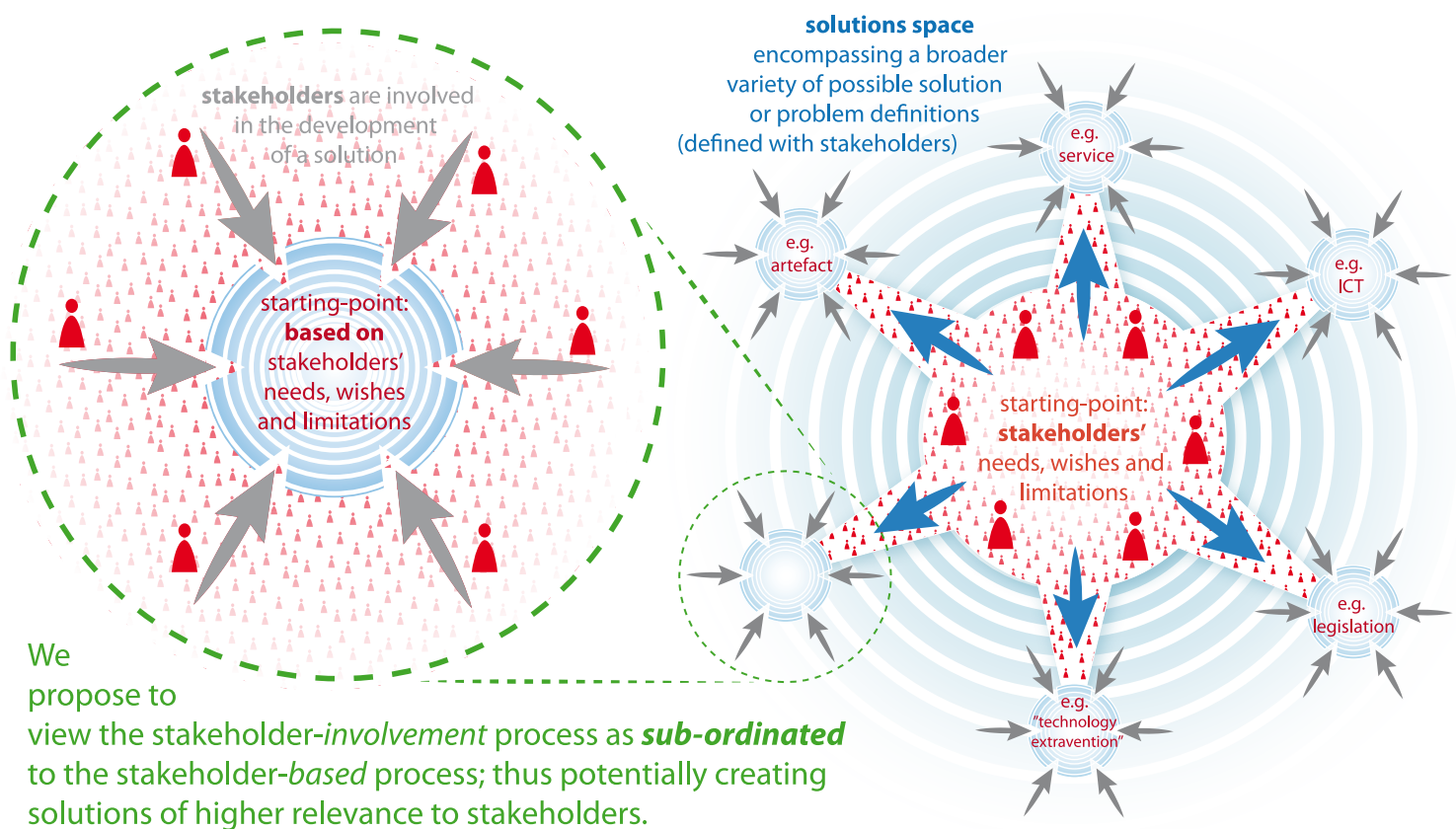

Figure 3: The stakeholder-involvement process (left illustration) depicted as a sub-ordinated process in the stakeholder-based process; having the stakeholder's needs, wishes and limitations as its central onset or starting-point (right illustration).

tion. The designers, as described in the case above, re-framed the initial problem (Dorst, 2011), and came to the conclusion that the real problem was concerned with how to strengthen the identity of the municipality. They questioned the initial solutions space (to design a souvenir based on spill material from a local industry), taking a more holistic perspective of the stakeholders needs (to strengthen the identity and the experience for inhabitants as well as visitors of Olofström).

\section{Stakeholder-based development as a pre-process to stakeholder involvement}

For a skilled designer, the pre-process of questioning the initial need and starting-point of a project may of course direct the development towards an ICT related solution, but it might just as well end up in e.g. a service, a new legislation, an artefact, a "technology extravention", etc. Both design onsets (stakeholderinvolvement and stakeholder-baseddevelopment) may result in an initially intended solution. The difference is that a stakeholder-based onset to design (as commonly conducted by industrial designers) opens up for more potentially relevant solutions, thus supporting solutions that are relevant to stakeholders (i.e. developing the right solution) rather than solutions adapted to stakeholders (i.e. potentially developing the wrong solution). (See figure 3)

Conducting stakeholder studies in early phases is crucial and requires a genuine interest for the stakeholders' perspectives (Krippendorff, 2006). It also requires skills to observe behaviours that can reveal the unspoken, and to ask questions to understand and penetrate hidden issues and unseen possibilities. Designers need to have the courage to question the initial design-brief of their client, and to actively work on avoiding any type of design fixation.

\section{Discussion}

Would it be possible to attain a more holistic understanding of design in HCI research, and engage in potential solutions or studies that not necessarily would involve ICT? What would happen if ICT would be understood as one of several potential solutions, in favour of coming closer to a humanistic understanding of human needs, drivingforces and limitations? Or if needs were understood without connection to ICT? Would HCI as a field loose its identity, or would the result be the creation of more socially and environmentally sustainable solutions?

We argue that $\mathrm{HCI}$ research has a dominant position in design-related research, and that there is a problem, which concerns the articulation of good design skills and design activities. As industrial designers we argue that the understanding of design needs to go beyond technological explorations or peoples' needs relating to ICT. A more holistic perspective of potential needs and potential solutions could support 


\section{This case illustrates how the industrial designer's approach to design commonly involves to study and to question the initial assignment before commencing the design process or creating any solution"}

HCI research to articulate design without an ICT fixation. This would open up for a greater perspective on design skills and design activities, and to create and understand a greater variety of solutions and their impact on society.

We hope to contribute with an industrial design perspective to the discourse of problematizing the role of ICT in HCI research, which several researchers already are engaged in (e.g. Baumer et al., 2015; Baumer \& Silberman, 2011; Pierce, 2012; Satchell \& Dourish, 2009). In general, we are positive about the possibilities that ICT gives society, and agree with others that current and new technology is, and will become ever more ubiquitous, thus having a large importance in society (Löwgren Q S Stolterman, 2004). However, defining a field of research by its tool (i.e. ICT) may mislead research towards areas that might be better addressed by other tools or solutions. This means that time and resources are put on developing knowledge and/or products/systems that not only become "less good", but also in itself hinder other work that indeed does ask for ICT to be involved; by factually taking time in itself, but most importantly, by keeping the design-research direction within HCI directed by its ICT-blinders. Our contribution is thus a clarification of how the practicing industrial designer's perspective supports focusing more on the stakeholder and to reflect on consigning the use of ICT to a sub-ordinated design process.

Our approach of linking industrial design practice to HCI research opens up for understanding how HCI research could benefit from design practitioners' perspectives and skills, rather than the other way around. Potentially, this can also lead to reducing the gap between design practitioners and researchers, as industrial design practitioners could contribute better with their competence when participating in HCI research projects.

\section{Conclusion}

In this paper we have problematized the notion of 'design' as used in HCI research, from an industrial design practitioner perspective. We discuss how questioning and reframing the initial design-brief is an essential design skill that can increase the value of the design contribution. Being fixated on solutions within a given pre-defined area such as e.g. ICT creates a fixation and may thus negatively affect both the contribution and the articulation of design. We believe that this is a relevant consideration for HCI research, in order to open up for more socially and environmentally sustainable solutions and to improve the articulation of design in general.

Anna Thies, industrial designer MFA, Clinical Innovation Fellow, PhD student at Dept. of Computer and Systems Sciences, Stockholm University,

Sara Ljungblad, PhD Human Machine Interaction, researcher and lecturer in interaction design at Applied IT, Gothenburg University,

Iréne Stewart Claesson, industrial designer MFA, design strategist, CEO/Partner at Lots Design AB, Gothenburg.

\section{References}

Bardzell, J., Bardzell, S., DiSalvo, C., Gaver, B., \& Sengers, P. (20I2). The Humanities and/in HCI. In Proceedings of the 2012 ACM annual conference on Human Factors in Computing Systems Extended Abstracts (pp. II35-II38). New York, NY, USA.

Baumer, E. P. S., Burrell, J., Ames, M. G., Brubaker, J. R., \& Dourish, P. (20I5). On the importance and implications of studying technology non-use. Interactions, 22(2), 52-56. doi:Io.II45/2723667

Baumer, E. P. S., \& Silberman, M. S. (2OII). When the Implication is Not to Design (Technology). In Proceedings of the 2OII annual conference on Human factors in computing systems - CHI 'II (p. 227I). New York, New York, USA: ACM Press. doi:Io.II45/I978942.I979275

Boehner, K., Vertesi, J., Sengers, P., \& Dourish, P. (2007). How HCI Interprets the Probes. In CHI'o7 (pp. I077-I086). San Jose, CA, USA: ACM.

Buchanan, R. (I992). Wicked Problems in Design Thinking. Design Issues, 8(2), 5-2I.

Buchenau, M., \& Suri, J. F. (2000). Experience prototyping. Proceedings of the Conference on Designing Interactive Systems Processes, Practices, Methods, and Techniques - DIS 'oo, 424-433.

Buxton, B. (2007). Sketching User Experiences: Getting the Design Right and the Right Design (Interactive Technologies). Morgan Kaufmann.

Dorst, K. (20I0). The Nature of Design Thinking. In K. Dorst, S. Stewart, I. Staudinger, B. Paton, \& A. Dong (Eds.), 8th Design Thinking Research Symposium (DTRS8) (pp. I3I-I39). Sydney, Australia: DAB documents.

Dorst, K. (20II). The core of "design thinking" and its application. Design Studies, 32(6), 52I-532. doi:IO.IOI6/ j.destud.20II.07.006

Dourish, P. (2006). Implications for Design. In Proceedings of the SIGCHI conference on Human factors in computing systems CHI 'o6 (pp. 54I-550). New York, NY, USA: ACM.

Fallman, D. (2003). Design-Oriented Human-Computer Interaction. In SIGCHI 
Conference on Human Factors in Computing Systems (CHI'o3) (pp. 225-232). New York, NY, USA: ACM.

Forlizzi, J., Zimmerman, J., \& Stolterman, E. (2009). From design research to theory: Evidence of a maturing field. In Proceedings of IASDR'o9.

Frankel, L., \& Racine, M. (20I0). The Complex Field of Research: for Design, through Design, and about Design. In Design Research Society. Montreal.

Freire, K., \& Sangiorgi, D. (20I0). Service Design \& Healthcare Innovation: from consumption to co-production and co-creation. In Second Nordic Conference on Service Design and Service Innovation.

Goodman, E., Stolterman, E., \& Wakkary, R. (2OII). Understanding interaction design practices. In Proceedings of the 20II annual conference on Human factors in computing systems - CHI 'II (pp. IO6I-IO70). New York, New York, USA: ACM Press. doi:Io.II45/I978942.I979100

Hutchinson, H., Hansen, H., Roussel, N., Eiderbäck, B., Mackay, W., Westerlund, B., ... Evans, H. (2003). Technology probes. In Proceedings of the conference on Human factors in computing systems - CHI 'o3 (p. I7). New York, New York, USA: ACM Press. doi:Io.II45/6426II.6426I6

Iacucci, G., Kuutti, K., \& Ranta, M. (2000). On the Move with a Magic Thing : Role Playing in Concept Design of Mobile Services and Devices. In D. Boyarski \& W. A. Kellogg (Eds.), Proceedings of the 3 rd conference on designing interactive systems: processes, practices, methods, and techniques (DIS'oo). New York, NY, USA: ACM.

Jahnke, M. (20I3). Meaning in the Making: Introducing a hermeneutic perspective on the contribution of design practice to innovation.

Jansson, D. G., \& Smith, S. M. (I99I). Design fixation. Design Studies, I2(I), 3-II. doi:Io.Ior6/oI42-694X(9I)90003-F

Johansson-Sköldberg, U., Woodilla, J., \& Çetinkaya, M. (20I3). Design Thinking: Past, Present and Possible Futures. Creativity and Innovation Management, 22(2), I2I-I46. doi:IO.IIII/caim.I2O23

Koskinen, I., Zimmerman, J., Binder, T. Redstrom, J., \& Wensveen, S. (20II). Design Research through Practice: From the Lab,
Field, and Showroom. Elsevier. Krippendorff, K. (2006). The Semantic Turn: A New Foundation for Design. CRC/ Taylor \& Francis.

Ljungblad, S., \& Holmquist, L. E. (2007). Transfer Scenarios : Grounding Innovation with Marginal Practices. In CHI'o7 (pp. 737-746). San Jose, CA, USA: ACM.

Löwgren, J., \& Stolterman, E. (2004). Thoughtful Interaction Design: A Design Perspective on Information Technology. Cambrige, Mass.: MIT Press.

Mullaney, T., \& Stolterman, E. (20I4). Why "design research practice" is not design as we know it.

Norman, D. (2004). Emotional design: Why we love (or hate) everyday things. Basic Books.

Pierce, J. (20I2). Undesigning Technology: Considering the Negation of Design by Design. In Proceedings of the 2012 ACM annual conference on Human Factors in Computing Systems - CHI 'i2 (p. 957). New York, New York, USA: ACM Press. doi:Io.II45/2207676.2208540

Purcell, A. T., \& Gero, J. S. (I996). Design and other types of fixation. Design Studies, I7(4), 363-383. doi:Io.Ior6/SoI42694X(96)00023-3

Rhea, D. (2003). Bringing clarity to the "Fuzzy Front End". A predictable process for innovation. In B. Laurel (Ed.), Design Research: Methods and Perspectives. MIT Press.

Roedl, D. J., \& Stolterman, E. (20I3). Design research at $\mathrm{CHI}$ and its applicability to design practice. In Proceedings of the SIGCHI Conference on Human Factors in Computing Systems - CHI 'I3 (pp. I95I-I954). New York, New York, USA: ACM Press. doi:Io.II45/2470654.2466257

Rogers, Y. (2004). New theoretical approaches for human-computer interaction. In B. Cronin (Ed.), Annual review of information, science and technology: Vol. 38 (pp. 87-I43). Medford, NJ: Information Today.

Satchell, C., \& Dourish, P. (2009). Beyond The User: Use And Non-Use in HCI. Proceedings of the 2Ist Annual Conference of the Australian Computer-Human Interaction Special Interest Group: Design: Open 24/7, (November), 9 - I6 doi:IO.II45/I738826.I738829
Sengers, P., \& Gaver, B. (2006). Staying Open to Interpretation: Engaging Multiple Meanings in Design and Evaluation. In Proceedings of the 6 th conference on Designing Interactive Systems (DIS'o6) (pp. 99-I08). New York, NY, USA: ACM.

Smith, A. M., \& Fischbacher, M. (2000). Stakeholder involvement in the new service design process. Journal of Financial Services Marketing, 5(I), 2I-3I. doi:IO.IO57/ palgrave.fsm.4770003

Stolterman, E. (2008). The Nature of Design Practice and Implications for Interaction Design Research. International Journal of Design, 2(I)

Stolterman, E., \& Pierce, J. (20I2). Design tools in practice. In Proceedings of the Designing Interactive Systems Conference on - DIS 'I2 (p. 25). New York, New York, USA: ACM Press. doi:Io.II45/23I7956.23I796I

Valtonen, A. (2005). Six decades - and six different roles for the industrial designer . In Nordes 2005 - In the making. Royal Danish Academy of Fine Arts, School of Architecture.

Valtonen, A. (2007). Redefining industrial design: changes in the designpractice in Finland. Helsinki: University of Art and Design Helsinki.

Verganti, R. (2009). Design Driven Innovation: Changing the Rules of Competition by Radically Innovating What Things Mean. Harvard Business School Publishing Corporation.

Vetting Wolf, T., Rode, J. A., Sussman, J., \& Kellogg, W. A. (2006). Dispelling Design as the "Black Art" of CHI. In Proceedings of the SIGCHI conference on Human Factors in computing systems - CHI 'o6 (pp. 52I-530). Montréal, Québec, Canada: ACM Press. doi:IO.II45/II24772.II24853

Wrigley, C., \& Bucolo, S. (20II). Teaching Design Led Innovation : The Future of Industrial Design. Design Principles and Practices, 5(2), 23I-240.

Zimmerman, J., Forlizzi, J., \& Evenson, S. (2007). Research through design as a method for interaction design research in HCI. In Proceedings of the SIGCHI conference on Human factors in computing systems - CHI 'o7 (pp. 493-502). New York, New York, USA: ACM Press. doi:IO.II45/I240624.I240704 